\title{
Kinetic Drying and Mathematical Modeling of Apple Slices on Dehydration Process
}

\section{Mohammad Zarein ${ }^{1 *}$, Seyed Hashem Samadi ${ }^{2}$ and Barat Ghobadian ${ }^{2}$}

${ }^{1}$ Department of Engineering, Shahre-Ray Branch, Islamic Azad University, Shahre Ray, Iran

${ }^{2}$ Department of Agricultural Machinery Engineering, Agricultural Faculty, Tarbiat Modares University, Tehran, Iran

\begin{abstract}
The hot air convective drying characteristics of thin layer apple slices were evaluated in a laboratory scale dryer In this study, the required energy for dehydration of apple slices was supplied of the hot air drying. Drying behavior of apple slices was studied at 4 temperature levels $\left(50,65,80\right.$, and $\left.95^{\circ} \mathrm{C}\right)$, and at three levels of drying material thickness $(3,5$, and $7 \mathrm{~mm})$ with the constant airflow velocity of $1 \mathrm{~m} / \mathrm{s}$. Empirical data of experiments with variants of semi-theoretical and empirical models were evaluated. Finally, the results indicated that the Midilli et al. model was most adequate in predicting moisture transfer and root mean square error (RMSE), chi-square $\left(X^{2}\right)$ and coefficient of determination $\left(R^{2}\right)$ were used for the determination of the best suitable model. The values of $R^{2}, X^{2}$ and RMSE at $95^{\circ} \mathrm{C}$ of hot air temperature for $3 \mathrm{~mm}$ of apple slices are obtained as $0.9979,0.000092$ and 0.01044 respectively.
\end{abstract}

Keywords: Hot air dryer; Dehydration; Mathematical model; Apple slice

\section{Introduction}

Apple is the pomaceous fruit of the apple tree, species Malus domestica in the rose family (Rosaceae). Apple is an important raw material for many food products. Apple plantations are cultivated all over the world in many countries. It is the fourth most important world fruit crop following all citrus types, grapes, and bananas [1]. Dehydration of fruit and vegetables is one of the oldest methods of food preservation and it is one of the most common processes used to improve food stability $[2,3]$. Dried or dehydrated fruits and vegetables can be produced by a variety of methods that depend on the type of food and the type of characteristics of the final product. Using proper drying methods, a large portion of damages to products during storage and handling could be prevented [4]. Dehydration occurs by vaporization of the liquid by supplying heat to the wet feedstock. Heat may be supplied by conduction (contact or indirect dryers), by convection (direct dryers), by radiation or volumetrically by placing the wet material in a microwave or radio frequency electromagnetic field. Over $85 \%$ of industrial dryers are of convective type with hot air or direct combustion gases as the drying medium [5]. Hot air drying both decreases drying time and improves the quality of dried product. The intermittent change of hot air temperature adversely affected appearance, color, firmness and taste of apple slices dried in a cabinet dryer [6]. Knowledge of the drying kinetics of biological materials is essential to the design, optimization and control of the drying processes. Several studies have been carried out to investigate the drying behavior of apple slices. However, no data on the drying behavior of the apple slices (cultivar of Golab) are available for engineering design of drying. Therefore, the present study was conducted to determine the effect of air temperature and sample thickness on the drying behavior of the Golab apple slices in a convective hot-air dryer.

\section{Materials and Methods}

\section{Materials}

In this study, apple slices were used to conduct the experiments. The study samples were freshly provided from a local market of Tehran. Then apples washed with tap and sliced as cylindrical shape with diameter of $60 \mathrm{~mm}$ and thicknesses of 3,5 and $7 \mathrm{~mm}$. Finally samples were placed on the hot air drying chamber. A hot air dryer employed which can be able to adjust the hot air temperature between 20 to $150^{\circ} \mathrm{C}$ and the air velocity between 0.1 to $2 \mathrm{~m} / \mathrm{s}$. Hot air parameters were adjusted by measuring temperature and velocity using a thermometer (Lutron, TM-925, Taiwan) and anemometer (Anemometer, LutronYK, 80AM, Taiwan). Drying process continued until the weight of samples did not change. During the drying experiments, the variation

\begin{tabular}{|l|l|l|}
\hline Model & Mathematical Function & Ref. \\
\hline Wang and Singh & $M R=a t^{2}+b t+c$ & {$[8]$} \\
\hline Henderson and Pabis & $M R=a \exp (-k t)$ & {$[9]$} \\
\hline Logaritmic & $M R=a \exp (-k t)+c$ & {$[10]$} \\
\hline Modified Page & $M R=\exp \left(-(k t)^{n}\right)$ & {$[11]$} \\
\hline Approximation of diffusion & $M R=a \exp (-k t)+(1-a) \exp (-k b t)$ & {$[12]$} \\
\hline page & $M R=\exp \left(-k t^{n}\right)$ & {$[8]$} \\
\hline Modified Henderson and Pabis & $M R=a \exp (-k t)+b \exp (-g t)+c \exp (-h t)$ & {$[13]$} \\
\hline Newton & $M R=\exp (-k t)$ & {$[8]$} \\
\hline Midili et al. & $M R=a \exp \left(-k t^{n}\right)+b t$ & {$[8]$} \\
\hline
\end{tabular}

$\mathrm{a}, \mathrm{b}, \mathrm{c}, \mathrm{k}$ and $\mathrm{n}$ are constant of models.

Table 1: Standard models reported in the literature used for drying of agricultura products.

*Corresponding author: Mohammad Zarein, Department of Engineering Shahre-Ray Branch, Islamic Azad University, Shahre Ray, Iran, E-mail: m.zarein@yahoo.com

Received April 22, 2013; Accepted June 27, 2013; Published July 05, 2013

Citation: Zarein M, Samadi SH, Ghobadian B (2013) Kinetic Drying and Mathematical Modeling of Apple Slices on Dehydration Process. J Food Process Technol 4: 247. doi:10.4172/2157-7110.1000247

Copyright: ( 2013 Zarein M, et al. This is an open-access article distributed under the terms of the Creative Commons Attribution License, which permits unrestricted use, distribution, and reproduction in any medium, provided the original author and source are credited. 
range of ambient temperature was $25 \pm 3^{\circ} \mathrm{C}$ and of ambient relative humidity was $24 \pm 4 \%$. The AOAC standard (1980) was employed to measure the initial moisture content (MC) of apple slices. The initial MC of apple slices were $86.2 \%$ (w.b.).

\section{Mathematical modeling}

In thin layer drying model, the rate of change in material moisture content in the falling rate drying period is proportional to the instantaneous difference between material moisture content and the expected material moisture content when it comes into equilibrium with the drying air. It is assumed that the material layer is thin enough or the air velocity is high so that the conditions of the drying air (humidity and temperature) are kept constant throughout the material. Nine moisture ratio models were fitted to the experimental drying data (Table 1). These models are typically derived by simplifying the general series solutions of Fick's second law and considering a direct relationship between the average water content and drying time [7].

Moisture ratio values for apple slices during the drying were calculated using equation (1):

$$
M R=\frac{M_{t}-M_{e}}{M_{o}-M_{e}}
$$

where, $M R$ is the moisture ratio (dimensionless), $M_{t}$ is the moisture content at any given time ( $\mathrm{kg}$ water/ $\mathrm{kg}$ solids), $\mathrm{M}_{\mathrm{e}}$ is equilibrium moisture content ( $\mathrm{kg}$ water $/ \mathrm{kg}$ solids) and $\mathrm{M}_{\mathrm{o}}$ is the initial moisture content. As $M_{e}$ is much lower than $M_{o}$ and $M_{t}$, it is negligible [8], then the equation could be simplified as follows:

$$
\mathrm{MR}=\frac{\mathrm{M}_{\mathrm{t}}}{\mathrm{M}_{0}}
$$

Three different criteria were used for evaluation of the fit: correlation coefficient, $R^{2}$; chi-squared, $\chi^{2}$, and Root Mean Square Error, RMSE. The most suitable model for describing drying characteristics of apple slices would be a model with the highest $R^{2}$ and the lowest $\chi^{2}$ and RMSE values.

$$
\begin{aligned}
& R^{2}=\frac{\sum_{i=1}^{N}\left(M R_{\text {exp }, i}-\overline{M R}_{\exp }\right)\left(M R_{\text {pre }, i}-\overline{M R}_{p r e}\right)}{\sqrt{\sum_{i=1}^{N}\left(M R_{\text {exp }, i}-\overline{M R}_{\exp }\right)^{2} \sum\left(M R_{p r e, i}-\overline{M R}_{p r e}\right)^{2}}} \\
& \chi^{2}=\frac{\sum_{i=1}^{N}\left(M R_{\text {exp }, i}-M R_{p r e, i}\right)^{2}}{N-m} \\
& R M S E=\left(\frac{1}{N} \sum_{i=1}^{N}\left(M R_{\text {pre }, i}-M R_{\text {exp }, i}\right)^{2}\right)^{\frac{1}{2}}
\end{aligned}
$$

$\mathrm{MR}_{\text {exp.i }}$ is the $\mathrm{i}_{\text {th }}$ moisture ratio value determined experimentally, $\mathrm{MR}_{\text {pre, }}$ is the $\mathrm{i}_{\text {th }}$ predicted moisture ratio value, $\mathrm{N}$ denotes the number of observations and $\mathrm{m}$ is the number of drying constants. The drying rate of apple slice was calculated using equation (6) [9].

$$
\text { Drying Rate }=\frac{\mathrm{M}_{\mathrm{t}+\mathrm{dt}-} \mathrm{M}_{\mathrm{t}}}{\mathrm{dt}}
$$

Where, $\left(M_{t+d t}\right)$ is moisture content at time $(t+d t)(\mathrm{kg}$ water/ kg dry matter), $M_{t}$ is moisture content at time $t$ (kg water/ kg dry matter) and $t$ is drying time ( $\mathrm{min})$.
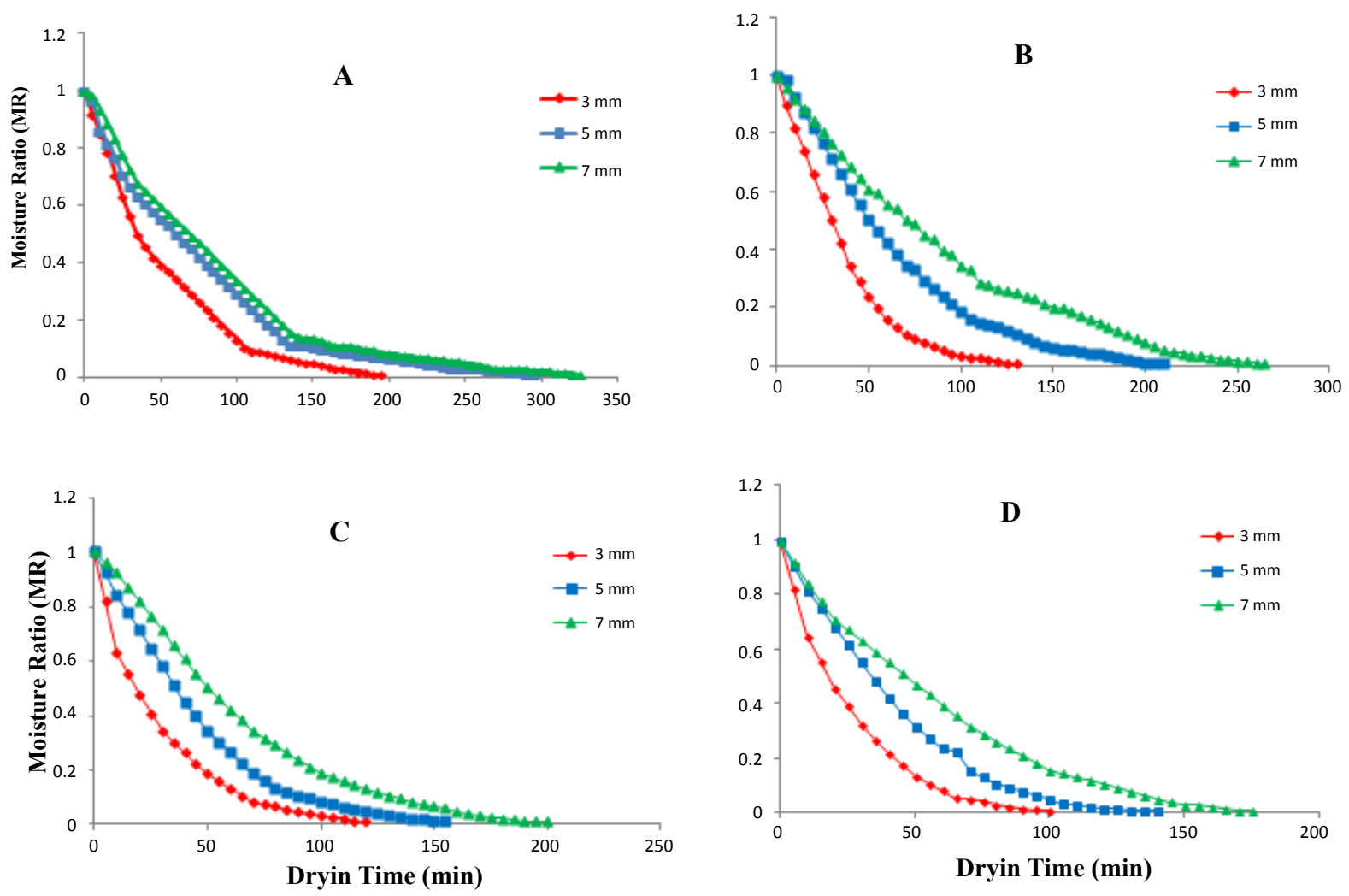

Figure 1: Thin-layer drying curves of apple slices in different temperature of dryer (A) $50^{\circ} \mathrm{C},(\mathrm{B}) 65^{\circ} \mathrm{C}(\mathrm{C}) 80^{\circ} \mathrm{C}$ and $(\mathrm{D}) 95^{\circ} \mathrm{C}$. 
Citation: Zarein M, Samadi SH, Ghobadian B (2013) Kinetic Drying and Mathematical Modeling of Apple Slices on Dehydration Process. J Food Process Technol 4: 247. doi:10.4172/2157-7110.1000247

Page 3 of 4

\section{Results and Discussion}

Figure 1 shows the time required for drying different apple slices at different temperatures and thicknesses. According to curves in this figure, the minimum drying time of apple slices occurred at high temperature $\left(95^{\circ} \mathrm{C}\right)$ and $3 \mathrm{~mm}$ thickness while its maximum was at low temperature $\left(50^{\circ} \mathrm{C}\right)$ and $7 \mathrm{~mm}$ thickness. As shown in this curves, increasing the temperature caused to decrease in drying time since both the thermal gradient inside the object and the evaporation rate of the product increase. In the drying of apple slices with hot air flow, the time required for heating up the whole mass of an apple thin layer to reach the evaporation point via thermal conduction inward the product's layer is prolonged due to its low thermal conduction. Additionally, at fixed temperature, the drying time increases as the product becomes thicker. This is mainly because, as the product's thickness increases, the moisture dissipation inside the product and, finally, its departure would face more resistance. Therefore, the drying process is prolonged.
On the other hand, since the drying occurs initially at the outer layer, the product is then dried and its permeability is therefore decreased (hardening phenomenon). This hardened layer imposes a barrier against the dissipation of moisture across the product's surface and prolongs its departure from the product. Similar results were reported in other research works for drying of pomegranate seeds [10-12].

The measurement of initial moisture content of apple slices using the weight-based method showed that the initial MC was $86.2 \%$ (w.b.). Using Eq. 2, values for moisture ratio (MR) at different temperatures and apple layer thicknesses were obtained. The obtained MR from the drying of apple slices at different temperatures and thicknesses were fitted to the introduced models in table 1 . Accuracy of different thinlayer drying models were evaluated based on $\mathrm{R}^{2}, \chi^{2}$ and RMSE values and the most accurate model was selected with regard to higher $\mathrm{R}^{2}$ and lower $\chi^{2}$ and RMSE. Results of fitting different models with data from apple drying showed that the model proposed by Midelli et al. predicts

\begin{tabular}{|c|c|c|c|c|c|c|c|c|c|}
\hline \multirow[t]{2}{*}{ Model name } & \multicolumn{3}{|c|}{$3 \mathrm{~mm}$} & \multicolumn{3}{|c|}{$5 \mathrm{~mm}$} & \multicolumn{3}{|c|}{$7 \mathrm{~mm}$} \\
\hline & $R^{2}$ & $X^{2}$ & RMSE & $R^{2}$ & $X^{2}$ & RMSE & $R^{2}$ & $X^{2}$ & RMSE \\
\hline \multicolumn{10}{|l|}{$50^{\circ} \mathrm{C}$} \\
\hline Newton & 0.9898 & $8.15 \times 10^{-4}$ & 0.03029 & 0.9914 & $2.32 \times 10^{-4}$ & 0.02563 & 0.9899 & $8.03 \times 10^{-4}$ & 0.02857 \\
\hline Page & 0.9974 & $2.06 \times 10^{-4}$ & 0.01456 & 0.9934 & $4.99 \times 10^{-4}$ & 0.02275 & 0.9964 & $2.94 \times 10^{-4}$ & 0.01729 \\
\hline Modified Page & 0.9971 & $2.86 \times 10^{-4}$ & 0.01656 & 0.9937 & $4.78 \times 10^{-4}$ & 0.02206 & 0.9964 & $2.94 \times 10^{-4}$ & 0.01729 \\
\hline Wang and Singh & 0.9772 & 0.001800 & 0.04314 & 0.9755 & 0.00100 & 0.04355 & 0.9822 & 0.00140 & 0.03835 \\
\hline Henderson & 0.9964 & $2.82 \times 10^{-4}$ & 0.01704 & 0.9918 & $6.23 \times 10^{-4}$ & 0.02519 & 0.9934 & $5.34 \times 10^{-4}$ & 0.02330 \\
\hline Logarithmic & 0.9939 & $4.69 \times 10^{-4}$ & 0.02133 & 0.9934 & $4.99 \times 10^{-4}$ & 0.02275 & 0.9964 & $4.4 \times 10^{-4}$ & 0.02132 \\
\hline Approximation of diffusion & 0.9974 & $2.09 \times 10^{-4}$ & 0.01487 & 0.9914 & $6.52 \times 10^{-4}$ & 0.02599 & 0.9965 & $2.86 \times 10^{-4}$ & 0.01720 \\
\hline Modified Page Equation-II & 0.8281 & 0.0013 & 0.01201 & 0.9937 & $4.78 \times 10^{-4}$ & 0.02225 & 0.9964 & $2.94 \times 10^{-4}$ & 0.01743 \\
\hline Midilli & 0.9979 & $1.7 \times 10^{-4}$ & 0.01357 & 0.9943 & $4.32 \times 10^{-4}$ & 0.02135 & 0.9887 & 0.00033 & 0.05884 \\
\hline \multicolumn{10}{|l|}{$65^{\circ} \mathrm{C}$} \\
\hline Newton & 0.9834 & 0.00100 & 0.03971 & 0.9815 & 0.001 & 0.04237 & 0.9873 & 0.00100 & 0.03282 \\
\hline Page & 0.9969 & $2.65 \times 10^{-4}$ & 0.01101 & 0.9951 & $4.14 \times 10^{-4}$ & 0.0256 & 0.9962 & $3.24 \times 10^{-4}$ & 0.0182 \\
\hline Modified Page & 0.9968 & $2.95 \times 10^{-4}$ & 0.01501 & 0.9949 & $4.14 \times 10^{-4}$ & 0.06515 & 0.9962 & $3.24 \times 10^{-4}$ & 0.0182 \\
\hline Wang and Singh & 0.9936 & $6.04 \times 10^{-4}$ & 0.02508 & 0.9948 & $4.9 \times 10^{-4}$ & 0.02242 & 0.9944 & $4.76 \times 10^{-4}$ & 0.02205 \\
\hline Henderson & 0.9883 & 0.001 & 0.03408 & 0.9909 & $8.58 \times 10^{-4}$ & 0.02966 & 0.9908 & 0.00070 & 0.02820 \\
\hline Logarithmic & 0.9935 & $6.16 \times 10^{-4}$ & 0.02591 & 0.9961 & $3.79 \times 10^{-4}$ & 0.01995 & 0.9965 & $3.2 \times 10^{-4}$ & 0.01818 \\
\hline Approximation of diffusion & 0.9931 & $3.02 \times 10^{-4}$ & 0.01253 & 0.9916 & $4.11 \times 10^{-4}$ & 0.01573 & 0.9889 & $9.78 \times 10^{-4}$ & 0.03189 \\
\hline Modified Page equation-II & 0.9834 & 0.001 & 0.03971 & 0.9810 & 0.00014 & 0.04237 & 0.9873 & 0.00100 & 0.03282 \\
\hline Midilli et al. & 0.9978 & $1.65 \times 10^{-4}$ & 0.01101 & 0.9738 & 0.00023 & 0.006515 & 0.9962 & $3.24 \times 10^{-4}$ & 0.01820 \\
\hline \multicolumn{10}{|l|}{$80^{\circ} \mathrm{C}$} \\
\hline Newton & 0.9949 & 0.0003 & 0.01919 & 0.9864 & 0.0012 & 0.03536 & 0.9808 & 0.001 & 0.04258 \\
\hline Page & 0.9972 & 0.0001 & 0.01298 & 0.9953 & $2.65 \times 10^{-4}$ & 0.01826 & 0.9967 & $2.03 \times 10^{-4}$ & 0.012803 \\
\hline Modified Page & 0.9968 & 0.00012 & 0.01398 & 0.9962 & $2.41 \times 10^{-4}$ & 0.02123 & 0.9967 & $2.11 \times 10^{-4}$ & 0.018752 \\
\hline Wang and Singh & 0.9282 & 0.00500 & 0.07371 & 0.9945 & $5.08 \times 10^{-4}$ & 0.02292 & 0.9960 & 0.0003 & 0.01968 \\
\hline Henderson & 0.9965 & 0.00020 & 0.01635 & 0.9910 & $8.23 \times 10^{-4}$ & 0.02917 & 0.9899 & 0.0009 & 0.03125 \\
\hline Logarithmic & 0.9965 & 0.00020 & 0.01665 & 0.9975 & 0.000300 & 0.02041 & 0.9965 & 0.00033 & 0.01864 \\
\hline Approximation of diffusion & 0.9967 & 0.000123 & 0.01585 & 0.9984 & $2.67 \times 10^{-4}$ & 0.012787 & 0.9966 & 0.00012 & 0.01416 \\
\hline Modified Page equation-II & 0.9977 & 0.00012 & 0.01327 & 0.9802 & 0.00100 & 0.04437 & 0.9941 & 0.00021 & 0.02179 \\
\hline Midilli et al. & 0.9987 & $1.54 \times 10^{-4}$ & 0.01316 & 0.9974 & $5.12 \times 10^{-5}$ & 0.007535 & 0.9967 & 0.00012 & 0.005876 \\
\hline \multicolumn{10}{|l|}{$95^{\circ} \mathrm{C}$} \\
\hline Newton & 0.9967 & 0.00015 & 0.01993 & 0.9833 & 0.00157 & 0.03962 & 0.9882 & $9.99 \times 10^{-4}$ & 0.03162 \\
\hline Page & 0.9968 & 0.00016 & 0.02078 & 0.9975 & $2.33 \times 10^{-4}$ & 0.01558 & 0.9947 & $4.49 \times 10^{-4}$ & 0.02152 \\
\hline Modified Page & 0.9958 & 0.000172 & 0.02378 & 0.9974 & $2.03 \times 10^{-4}$ & 0.01456 & 0.9947 & $4.49 \times 10^{-4}$ & 0.02152 \\
\hline Wang and Singh & 0.9686 & 0.00200 & 0.05266 & 0.9976 & 0.00020 & 0.01545 & 0.9945 & $4.65 \times 10^{-4}$ & 0.02189 \\
\hline Henderson & 0.9971 & 0.00011 & 0.01929 & 0.9873 & 0.00110 & 0.03519 & 0.9894 & $9.0 \times 10^{-4}$ & 0.03044 \\
\hline Logarithmic & 0.9958 & 0.00019 & 0.02039 & 0.9962 & $3.56 \times 10^{-4}$ & 0.0196 & 0.9946 & $1.21 \times 10^{-4}$ & 0.01136 \\
\hline Approximation of diffusion & 0.7352 & 0.02220 & 0.01571 & 0.5400 & 0.043300 & 0.02166 & 0.6180 & 0.03200 & 0.01856 \\
\hline Modified Page equation-II & 0.9971 & 0.00013 & 0.01668 & 0.9833 & 0.00157 & 0.04112 & 0.9924 & $6.45 \times 10^{-4}$ & 0.02617 \\
\hline Midilli et al. & 0.9979 & 0.000092 & 0.01044 & 0.9962 & $1.58 \times 10^{-4}$ & 0.01349 & 0.9955 & $1.28 \times 10^{-4}$ & 0.01187 \\
\hline
\end{tabular}

Table 2: Statistical data obtained of various thin-layer drying models. 
Citation: Zarein M, Samadi SH, Ghobadian B (2013) Kinetic Drying and Mathematical Modeling of Apple Slices on Dehydration Process. J Food Process Technol 4: 247. doi:10.4172/2157-7110.1000247

the drying process of apple slices more accurately than other models. Results of fitting different models with laboratory data are presented in table 2.

\section{Conclusion}

The drying behavior of apple slices at four temperature levels (50, 65,80 , and $95^{\circ} \mathrm{C}$ ) and three sample thicknesses $(3,5$ and $7 \mathrm{~mm})$ at constant air velocity $(1 \mathrm{~m} / \mathrm{s})$ was studied and the following conclusions were drawn

Drying process of apple slices occurred in the falling rate period. Drying time decreased significantly with increasing hot air temperature. In addition, with increasing the thickness of samples drying time increased. Minimum and maximum of drying time was found for thickness of $3 \mathrm{~mm}$ (high temperature, $95^{\circ} \mathrm{C}$ ) and 7 $\mathrm{mm}$ (low temperature, $50^{\circ} \mathrm{C}$ ) of samples, respectively. Results of the mathematical modeling showed that the Midilli et al. model gave the best fit to the experimental data. For example, at $95^{\circ} \mathrm{C}$ of hot air temperature for $3 \mathrm{~mm}$ of apple slices, the values of $\mathrm{R}^{2}, \chi^{2}$ and RMSE are obtained as $0.9979,0.000092$ and 0.01044 respectively.

\section{References}

1. Forsline PL, Aldwinckle HS, Dickson EE, Luby JJ, Hokanson SC (2010) Collection, Maintenance, Characterization, and Utilization of Wild Apples of Central Asia. Horticultural Reviews: Wild Apple and Fruit Trees of Central Asia, John Wiley \& Sons.

2. Mandala IG, Anagnostaras EF, Oikonomou CK (2005) Influence of osmotic dehydration conditions on apple air-drying kinetics and their quality characteristics. J Food Eng 69: 307-316.
3. Sacilik K, Elicin AK (2006) The thin layer drying characteristics of organic apple slices. J Food Eng 73: 281-289.

4. Barbosa-Canovas GV, Vega-Mercado HV (1995) Dehydration of foods. Chapman and Hall, USA.

5. Dariusz P, Andrzej L (1999) Recent advances in the drying of apples under variable process conditions. Processing Foods: CRC Press, UK.

6. Doymaz I (2007) Influence of pretreatment solution on the drying of sour cherry J Food Eng 78: 591-596.

7. Motevali A, Minaei S, Khoshtaghaza MH, Kazemi M, Nikbakht MA (2010) Drying of Pomegranate Arils: Comparison of Predictions from Mathematical Models and Neural Networks. Int J Food Eng 6: 1-20.

8. Akpinar E, Midilli A, Bicer Y (2003) Single layer drying behaviour of potato slices in a convective cyclone dryer and mathematical modeling. Energ Convers Manage 44: 1689-1705.

9. Doymaz I, Ismail O (2011) Drying characteristics of sweet cherry. Food Bioprod Process 89: 31-38

10. Chhinnan MS (1984) Evaluation of Selected Mathematical Models fo Describing Thin-Layer Drying of In-Shell Pecans. Transactions of the ASAE 27: $610-615$

11. Motevali A, Abbaszadeh A, Minaei S, Khoshtaghaza M, Ghobadian B (2012) Effective Moisture Diffusivity, Activation Energy and Energy Consumption in Thin-layer Drying of Jujube. Journal of Agricultural Science and Technology 14: $523-532$

12. Motevali A, Minaei S, Khoshtagaza MH (2011) Evaluation of energy consumption in different drying methods. Energ Convers Manage 52: 1192 1199. 